\title{
Fake news and science denier attacks on vaccines. What can you do?
}

\author{
Noni E MacDonald ${ }^{1 *}$
}

\begin{abstract}
Misinformation and disinformation ("fake news") about vaccines are contagious-travelling faster and farther than truth. The consequences are serious; leading to negative impacts on health decisions, including vaccine acceptance, and on trust in immunization advice from public health and/or healthcare professional. This article provides a brief overview of evidence-based strategies to address vaccine deniers in public, in clinical practice and in social situations. As well, a strategy to help differentiate between vaccine deniers and simple vaccine refusers in a practice or clinic is provided. Five tactics are widely used by vaccine deniers: conspiracy; fake experts; selectivity; impossible expectations; and misrepresentation and false logic. Recognizing and understanding these tactics can help protect against misinformation and science denialism propaganda. Highlighting the strong medical science consensus on the safety and effectiveness of vaccines also helps. Carefully and wisely choosing what to say and speaking up-whether you are at a dinner party, out with friends or in your medical office or clinic-is crucial. Not speaking up implies you agree with the misinformation. Having healthcare providers recognize and address misinformation using evidence-based strategies is of growing importance as the arrival of the coronavirus disease 2019 (COVID-19) vaccines is expected to further ramp up the vaccine misinformation and disinformation rhetoric. Healthcare providers must prepare themselves and act now to combat the vaccine misinformation tsunami.
\end{abstract}

This work is licensed under a Creative Commons Attribution 4.0 Internationa License.

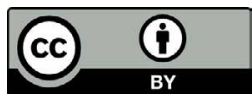

Affiliation

1 Department of Paediatrics, Dalhousie University, IWK Health Centre, Halifax, NS

*Correspondence: noni.macdonald@dal.ca

Suggested citation: MacDonald NE. Fake news and science denier attacks on vaccines. What can you do? Can Commun Dis Rep 2020;46(11/12):432-5. https://doi.org/10.14745/ccdr.v46i1112a11

Keywords: science denier, vaccine, misinformation, disinformation

\section{Introduction}

Never before has the public been so bombarded by information, nor has it ever been so difficult to know what and whom to believe. The critical importance of this problem is well illustrated by the World Health Organization (WHO) shining a bright light on the coronavirus disease 2019 (COVID-19) pandemic infodemic (1). Infodemic refers to a rapid and far-reaching spread of both accurate and inaccurate information. Misinformation (information that is false but not created with the intention of causing harm) and disinformation (or "fake news"; information that is false and deliberately created to cause harm) travel faster and farther than truth $(2,3)$. Science deniers, including vaccine science deniers, have a strong and very effective platform now - the Web-from which to shill their scientifically-bankrupt wares (4). We, who understand the rigor of science and know the evidence supporting immunization for health and well-being, are often aghast at the falsehoods promulgated and-too often-accepted and acted upon by members of the public. For example, in the United States, the variation in human papillomavirus (HPV) vaccine uptake across the country is better explained by exposure to tweets about HPV than by socioeconomic class data (5).

\section{Why does this happen?}

Sadly, we all make most of our decisions based upon our beliefs and not upon carefully weighed scientific evidence (6). We see and hear what we believe, rather than believing what we see and hear (7). We are strongly influenced by what we think others around us (our social networks) are doing or expecting us to do. We see causation in coincidences and we prefer anecdote and stories to data and scientific evidence.

The objective of this article is to draw attention to the importance of fake news and science deniers' attacks on vaccines in the era of social media. It will describe tactics used by science deniers and highlight strategies healthcare providers can use in their office or clinic when they encounter a vaccine refuser or a science denier as well as providing the URL for a WHO website for report concerning misinformation found online.

This is the ninth article produced by the Canadian Vaccination Evidence Resource and Exchange Centre (CANVax) in the CANVax Briefs series. This centre includes a group of multidisciplinary professionals that identify and create useful resources to foster vaccine uptake (8). 


\section{What can you do?}

What can you do in the face of this tsunami of misinformation and disinformation that is shaping negative beliefs about immunization amongst the general public, patients and even, occasionally, among our professional colleagues? Misinformation is indeed everybody's problem now (9). The consequences are serious, leading to negative impacts on health decisions, including vaccine acceptance, and on trust in immunization advice from public health and/or healthcare professional. This impact of misinformation and disinformation will become even more important when the COVID-19 vaccines arrive, with an expected further ramp up of vaccine disinformation (10). If counteractions are not taken, the antivaccine movement has the potential to overwhelm the pro-vaccine voices online (10). You can and should help combat this vaccine misinformation tsunami.

\section{Prepare yourself: know and recognize tactics used by vaccine deniers}

Know the five tactics used widely, often with great vigor, by vocal vaccine deniers on the Web, in mainstream media and in public appearances (11):

- Conspiracies-drug companies, the government, the health system-pick your scapegoat-are out to trick the general public; they withhold information, lie and cover up "the truth"

- Fake experts-quote or use fake experts and vigorously denigrate, even decry, real experts

- $\quad$ Selectivity-refer to obscure and or discredited papers that support their argument but omit the vast science that refute it

- Impossible expectations_vaccine must be $100 \%$ safe and effective-and yet no medical intervention is $100 \%$ safe and effective

- Misrepresentation and false logic-jump to erroneous conclusion and use false or illogical analogies

Interestingly, once you know these tactics they are easy to recognize, as is evidenced by the fake news complaints and the misinformation and disinformation appearing almost daily in the mainstream and social media.

\section{Teach your patients to recognize tactics of science deniers}

There are scientific studies that have shown that one way to protect the public against fake news and science deniers is to teach the public about the tactics used, not just correct the scientific misinformation being presented (12). If an internet site is the misinformation source, consider reporting it via the $\mathrm{WHO}$ website "How to report misinformation online" (13).

\section{Highlight scientific consensus}

Highlighting that there is scientific consensus on the benefits and value of immunization is also helpful (14) when reacting to fake news about vaccines and immunization. Share your sources of accurate and quality vaccine information with your patients. These steps will not convince the vocal vaccine denier but are helpful for those who are vaccine hesitant in your target audience-your patients and the general public.

\section{Addressing vocal vaccine deniers in public} The Regional Office for Europe of WHO has developed effective guidance on how to address vocal vaccine deniers in public $(15,16)$. This is not an easy task but is an important one to undertake if the vocal vaccine science denier is having, or has the potential to have, a significant negative impact on trust in immunization in your community.

The WHO guidance is primarily intended for spokespersons of health authorities who want to prepare themselves for a public event with a vocal vaccine denier, and provides advice on who should be the spokesperson, dos and don'ts of verbal and nonverbal communication, how to behave in a passionate discussion and how to protect yourself. It provides helpful and evidencesupported strategies if you should find yourself asked to speak in public.

An important point-do not participate in a public discussion if you are not media trained.

\section{Strategies to address a vaccine science denier in clinical practice}

\section{Differentiating between a science denier and a simple refuser}

The first and very important step is to determine if the patient not wanting to take the vaccine is a science denier or a "simple refuser". You may be able to quickly tease this out by asking: "What would it take to move you to a "yes" to accept this vaccine?" The simple refuser may pause, think and name the concern. This is even more likely if you have a good rapport and a trusting relationship with the patient. In contrast, you will get a very different reaction from the vaccine science denier. They most often start with a long list of concerns and want to work hard to persuade you to their viewpoint. Beware. 


\section{Strategies to use when addressing vaccine refusers}

Vaccine refusers usually have one or possibly two main concerns. When addressing the concern, heed the following advice:

- Do not make the session a "knowledge dump" as overwhelming the refuser with information is rarely helpful and may actually end up raising concerns about which the refuser was not previously worried

- Do not spend time refuting myths, as this does not change attitudes to immunization (17); furthermore, it may be the myths that the refuser remembers and not the correct information

- Mini motivational interviewing is a more helpful strategy to further understand concerns and move the patient towards acceptance $(18,19)$; WHO has a short conversation guide training module on this technique for immunization that you might find helpful (20)

\section{Strategies to use when addressing science deniers}

The term "vaccine denier" refers to a member of a subgroup at the extreme end of the hesitancy continuum; one who has a very negative attitude towards vaccination and is not open to a change of mind no matter what the scientific evidence says (11). There are several points to remember when addressing science deniers:

- Do not get into a debate with the denier; it is a time-wasting trap

- $\quad$ State that science is clearly behind immunization. Again, do this without getting into a debate: you are highly unlikely to convince the denier with your arguments and are likely to end up in a unhelpful "yes but" cycle

- You may try mini motivational interviewing as noted above. With strong vaccine science deniers, this is less likely to help than with simple refusers, but it is worth a try

\section{Leave the door open}

Regardless of whether the patient is a denier or a refuser, if they chose not to immunize their child or themselves that day, leave the door open for future visits and discussion. Do not dismiss them from your practice-even if that is tempting-as this is not in the best interests of the patient or the community (21). As well, it is clinically important to go over the risks and responsibilities if the patient chooses not to accept the vaccine(s). The Canadian Paediatric Society Caring for Kids website has advice on this that you can then retailor to fit your patient's situation (22).

\section{Do not remain silent}

Finally, remember do not remain silent when faced with a vaccine science denier, as your silence may be interpreted by the others around you that you are in agreement with the misinformation.
Choose carefully and wisely what to say and speak up-whether it is to a co-worker or a patient or friend. The target audience is not the denier, but those others around you. Remember to educate others about disinformation techniques being used and help to inoculate against fake news and science denial.

\section{Conclusion}

In light of fake news about vaccines and science deniers' attacks on vaccines proliferating on both mainstream and social media (10), it is critical to learn how to differentiate the real science deniers from vaccine refusers, and how to identify the simple refusers, who were made unsure in their vaccine acceptance beliefs by the machinations of science deniers. Knowing and using appropriate strategies for both groups empowers healthcare providers to appropriately address situations in professional as well as personal settings.

\section{Author's statement}

NEM-Conceptualization, writing of original draft, reviewing and editing.

\section{Competing interests}

NE MacDonald received grants from the Public Health Agency of Canada, the World Health Organization, the Nova Scotia Health Research Foundation, the Canadian Institutes of Health Research, the Canadian Immunization Research Network and the Social Sciences and Humanities Research Council of Canada. She is a member of the Canadian Vaccination Evidence Resource and Exchange Centre (CANVax) Team.

\section{Acknowledgements}

Production of the Canadian Vaccination Evidence Resource and Exchange Centre (CANVax) Briefs has been made possible through funding from the Public Health Agency of Canada. Thank you to the many authors, immunization partners and reviewers who contribute to CANVax.

\section{Funding}

The development of the Canadian Vaccination Evidence Resource and Exchange Centre Briefs is supported by the Immunization Partnership Funds of the Public Health Agency of Canada. 


\section{References}

1. World Health Organization. Infodemic management Infodemiology. WHO; 2020 (accessed 2020-10-08). https://www.who.int/teams/risk-communication/ infodemic-management

2. Bauch CT, Galvani AP. Epidemiology. Social factors in epidemiology. Science 2013;342(6154):47-9. DOI PubMed

3. Vosoughi S, Roy D, Aral S. The spread of true and false news online. Science 2018;359(6380):1146-51. DOI PubMed

4. Kata A. Anti-vaccine activists, Web 2.0, and the postmodern paradigm--an overview of tactics and tropes used online by the anti-vaccination movement. Vaccine 2012;30(25):377889. DOI PubMed

5. Dunn AG, Surian D, Leask J, Dey A, Mandl KD, Coiera E. Mapping information exposure on social media to explain differences in HPV vaccine coverage in the United States. Vaccine 2017;35(23):3033-40. DOI PubMed

6. Kahan DM. Social science. A risky science communication environment for vaccines. Science 2013;342(6154):53-4. DOI PubMed

7. Dubé È, MacDonald NE. Managing the risks of vaccine hesitancy and refusals. Lancet Infect Dis 2016;16(5):518-9. DOI PubMed

8. Canadian Public Health Association. The Canadian Vaccination Evidence Resource and Exchange Centre. Ottawa (ON): CANVax. https://www.canvax.ca

9. Donavan J, Wardle C. Misinformation is Everybody's Problem Now. Social Science Research Council. Items. Insights from the Social Science. SSRC; August 6, 2020 (accessed 2020-10-08). https://items.ssrc.org/covid19-and-the-social-sciences/mediated-crisis/misinformation-i s-everybodys-problem-now/

10. Burki T. The online anti-vaccine movement in the age of COVID-19. Lancet Digit Health 2020;2(10):e504-5. DOI PubMed

11. Schmid P, MacDonald NE, Habersaat $K$, Butler R. Commentary to: how to respond to vocal vaccine deniers in public. Vaccine 2018;36(2):196-8. DOI PubMed

12. van der Linden S, Maibach E, Cook J, Leiserowitz A, Lewandowsky S. Inoculating against misinformation. Science 2017;358(6367):1141-2. DOl PubMed

13. World Health Organization. How to report misinformation online. Geneva (Switzerland): WHO; 2020 (accessed 2020-10-08). https://www.who.int/campaigns/ connecting-the-world-to-combat-coronavirus/ how-to-report-misinformation-online
14. van der Linden SL, Clarke CE, Maibach EW. Highlighting consensus among medical scientists increases public support for vaccines: evidence from a randomized experiment. BMC Public Health 2015;15:1207. DOI PubMed

15. World Health Organization Regional Office for Europe. Best practice guidance: How to respond to vocal vaccine deniers in public (2017). WHO; 2017 (accessed 2020-10-08). https://www.euro.who.int/en/health-topics/ disease-prevention/vaccines-and-immunization/ publications/2016/best-practice-guidance-how-to-respond -to-vocal-vaccine-deniers-in-public-2017

16. Schmid P, Betsch $C$. Effective strategies for rebutting science denialism in public discussions. Nat Hum Behav 2019;3(9):931-9. DOl PubMed

17. Horne Z, Powell D, Hummel JE, Holyoak KJ. Countering antivaccination attitudes. Proc Natl Acad Sci USA 2015;112(33):10321-4. DOI PubMed

18. Gagneur A, Lemaître T, Gosselin V, Farrands A, Carrier N, Petit G, Valiquette $L$, De Wals $P$. A postpartum vaccination promotion intervention using motivational interviewing techniques improves short-term vaccine coverage: PromoVac study. BMC Public Health 2018;18(1):811. DOI PubMed

19. Gagneur A. Motivational interviewing: A powerful tool to address vaccine hesitancy. Can Commun Dis Rep 2020;46(4):93-7. DOl PubMed

20. World Health Organization. Immunization, Vaccine and Biologicals. Improving vaccination demand and addressing hesitancy. WHO (updated 2020-06; accessed 2020-10-08). http://www.who.int/immunization/programmes_systems/ vaccine_hesitancy/en/

21. MacDonald NE, Harmon S, Dube E, Taylor B, Steenbeek A, Crowcroft N, Graham J. Is physician dismissal of vaccine refusers an acceptable practice in Canada? A 2018 overview. Paediatr Child Health 2019;24(2):92-7. DOl PubMed

22. Canadian Paediatric Society. Caring for Kids. When parents choose not to vaccinate: Risks and responsibilities. CPS; August 2016 (accessed 2020-10-08). https://www. caringforkids.cps.ca/handouts/when-parents-choose-no t-to-vaccinate-risks-and-responsibilities 